\title{
ANALISIS PENYEDIAAN REKAM MEDIS PASIEN RAWAT JALAN BERDASARKAN STANDAR OPERASIONAL PROSEDUR (SOP) DI PUSKESMAS X
}

\author{
Fahmi Hakam \\ Program Studi Perekam \& Informasi Kesehatan, FKM, Universitas Veteran Bangun Nusantara \\ E-mail : fahmihakam.01@gmail.com
}

\begin{abstract}
ABSTRAK
Pelayanan yang cepat kepada pasien tidak lepas dari kerjasama antar unit dalam Puskesmas. Berdasarkan hasil obsevasi, ternyata masih ditumukan keterlambatan pendistribusian berkas rekam medis pasien rawat jalan. Tujuan dari penelitin ini, adalah untuk mengetahui pelaksanaan penyediaan berkas rekam medis rawat jalan berdasarkan Standar Operasional Prosedur (SOP), serta hambatan dalam pelaksanaannya. Metode yang digunakan dalam penelitian ini adalah jenis penelitian deskriptif kualitatif dengan rancangan cross sectional. Pelaksanaan penyediaan berkas rekam medis berdasarkan SOP distribusi rekam medis. Hambatan penyediaan berkas rekam medis: (1) belum adanya standar waktu pada SOP distribusi rekam medis, (2) perawat mengambil sendiri berkas rekam medis ke pendaftaran, (3) keterbatasan SDM.
\end{abstract}

Kata kunci : Rekam Medis, SOP, Penyediaan Berkas Rekam Medis.

\begin{abstract}
Rapid service to the patient can not be separated from the cooperation between units in Primary Healthcare. Based on the results of obsevation, it is still announced the delay of distribution of medical records of outpatients. The purpose of this research is to know the implementation of outpatient medical record file based on Standard Operating Procedure (SOP), as well as obstacles in its implementation. The method used in this research is descriptive qualitative research with cross sectional design. Implementation of medical records file based on SOP distribution of medical record. Barriers to the provision of medical record files: (1) there is no standard time in the SOP of the medical record distribution, (2) the nurse takes the medical record file to registration, (3) the limited human resources.
\end{abstract}

Keywords : Medical Record, SOP, Medical Record File of Provision

\section{PENDAHULUAN}

Menurut Kepmenkes No.128 Tahun 2004 tentang Kebijakan Dasar Puskesmas, Puskesmas merupakan unit pelaksanaan teknis Dinas Kesehatan Kabupaten/Kota yang bertanggungjawab menyelenggarakan pembangunan kesehatan di suatu wilayah kerja. Setiap sarana pelayanan kesehatan di wilayah Kecamatan yaitu Puskesmas wajib membuat rekam medis yang dibuat oleh dokter dan tenaga kesehatan yang terkait dengan pelayanan yang telah diberikan oleh dokter dan tenaga kesehatan lainnya (Kementrian Kesehatan Republik Indonesia 2014).

Menurut Permenkes RI No 269/Menkes/Per/III/2008 tentang Rekam Medis pada pasal 1, rekam medis adalah berkas yang berisikan catatan dan dokumen tentang identitas pasien, pemeriksaan, pengobatan, tindakan dan pelayanan lain yang telah diberikan kepada pasien.

Untuk mencapai tujuan rekam medis diperlukan upaya peningkatan mutu rekam medis oleh Unit Kerja Rekam Medis, dimana upaya peningkatan mutu tersebut sangat tergantung dari tersedianya data dan informasi yang jelas, akurat, terpercaya, dan penyajiannya yang tepat waktu. Data dan informasi kesehatan yang tercantum dalam berkas rekam medis sangat berguna bagi manajemen institusi pelayanan kesehatan untuk menilai 
pelayanannya, apakah bermutu, efisien, dan efektif.

Kecepatan dalam penyediaan berkas rekam medis ke poli menjadi salah satu indikator mutu pelayanan di rekam medis. Semakin cepat rekam medis sampai di poliklinik maka semakin cepat pelayanan yang diberikan kepada pasien (Abdullah 2013).

Berdasarkan pengamatan yang dilakukan oleh peneliti, bahwa proses penyediaan berkas rekam medis masih mengalami beberapa masalah, yaitu kurangnya SDM di pendaftaran, serta keaktifan dari perawat poli dalam mengambil berkas rekam medis ke pendaftaran. Keterlambatan penyediaan berkas rekam medis tersebut, berpengaruh terhadap pelayanan medis kepada pasien. Semakin lama penyediaan berkas rekam medis, maka semakin lama juga waktu pelayanan medis yang diberikan kepada pasien.

\section{METODE PENELITIAN}

Penelitian ini menggunakan pendekatan deskriptif kualitatif dengan rancangan cross sectional. Subjek dalam penelitian ini adalah petugas yang bertanggungjawab dalam proses pendaftaran 3 orang dan 1 kepala Puskesmas. Objek penelitian yaitu proses pelaksanaan penyediaan berkas rekam medis.

\section{HASIL}

\section{Jaminan Mutu Pelayanan}

1. Tarif sesuai PERDA Sleman : Tarif pelayanan yang berlaku, sesuai dengan Peraruran daerah di kab. Sleman.

2. Puskesmas Santun Lansia : Puskesmas memiliki program pelayanan pada kelompok lanjut usia.

3. Implementasi Pelayanan PRIMA, yang berdasarkan pada Service Excellence dan kepuasan pasien, sesuai dengan standar pelayanan yang berlaku.

4. Dalam mutu manajemen dan pelayanan yang ada, Puskesmas telah memiliki Sertifikasi ISO 2008 oleh PT.SGS

5. Merupakan Puskesmas PONED

6. Merupakan Puskesmas yang sudah Terakreditasi

\section{Penyediaan Berkas Rekam Medis Berdasarkan SOP}

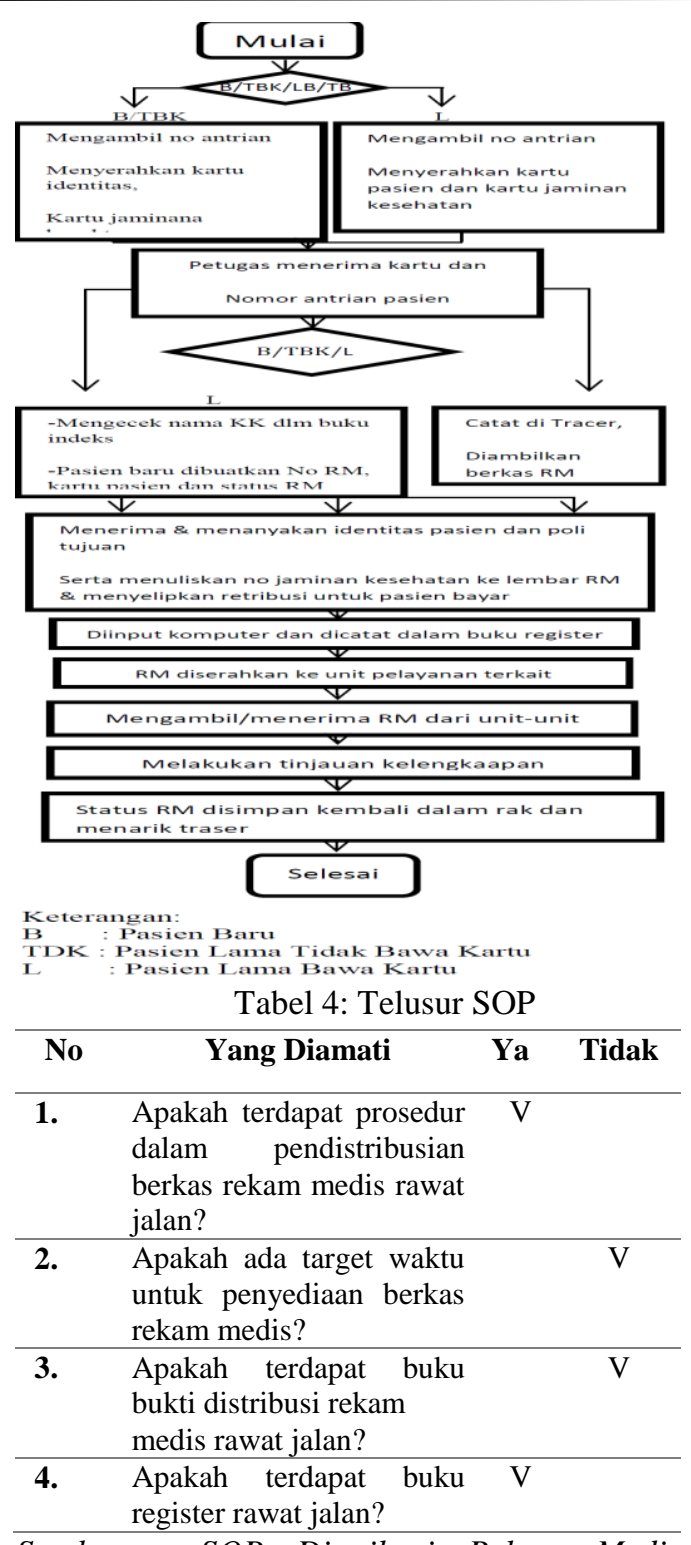

Sumber : SOP Distribusi Rekam Medis Puskesmas Minggir

Dari hasil wawancara dan studi dokumentasi, peneliti mendapat hasil pengetahuan petugas rekam medis tentang SOP, sistem SOP distribusi rekam medis dan evaluasi terkait SOP, yang pada pelaksanaannya kegiatan distribusi dan penyediaan berkas rekam medis tidak berdasarkan SOP yang berlaku dan petugas kurang memahami isi dari SOP.

Kurangnya pemahaman petugas terkait SOP yang ada, disebabkan karena sosialisasi tidak dilakukan secara menyeluruh dan berkelanjutan, serta tidak adanya mekanisme controlling dalam melakukan monitoring kesesuaian SOP dengan kegiatan yang berlangsung. 
Pelaksanaan penyediaan berkas rekam medis

Dari hasil observasi selama satu minggu, didapatkan bahwa adanya pelaksanaan penyediaan berkas rekam medis pasien rawat jalan dari pendaftaran ke poli yang dituju.

Tabel 5: Pelaksanaan Penyediaan Berkas Rekam Medis

\begin{tabular}{|c|c|c|c|}
\hline No & Yang Diamati & Ya & Tidak \\
\hline 1 & $\begin{array}{l}\text { Apakah petugas } \\
\text { menanyakan kartu pasien } \\
\text { lama rawat jalan? }\end{array}$ & $\mathrm{V}$ & \\
\hline 2 & $\begin{array}{l}\text { Apakah petugas filing } \\
\text { segera } \\
\text { permintaan berkas dari } \\
\text { tempat pendaftaran? }\end{array}$ & $\mathrm{V}$ & \\
\hline 3 & $\begin{array}{l}\text { Apakah ada petugas } \\
\text { khusus } \quad \text { yang } \\
\text { memintakan berkas } \\
\text { rekam medis dari } \\
\text { tempat pendaftaran } \\
\text { sampai ke poli }\end{array}$ & & V \\
\hline 4 & $\begin{array}{l}\text { Apakah kondisi fisik } \\
\text { berkas rekam medis rawat } \\
\text { jalan tersebut baik? }\end{array}$ & $\mathrm{V}$ & \\
\hline 5 & $\begin{array}{l}\text { Apakah terdapat rak } \\
\text { penyimpanan? }\end{array}$ & $\mathrm{V}$ & \\
\hline 6 & $\begin{array}{lr}\text { Apakah terdapat } & \text { alat } \\
\text { komunikasi } & \text { untuk } \\
\text { berhubungan } & \text { para } \\
\text { petugas? } & \end{array}$ & $\mathrm{V}$ & \\
\hline
\end{tabular}

Berdasarkan hasil wawancara dan didukung hasil pengamatan menyebutkan bahwa pelaksanaan penyediaan berkas rekam medis memiliki aturan yang mengatur penyediaan berkas rekam medis dan lama SOP diterapkan.

Pelaksanaan penyediaan dan distribusi berkas rekam medis sangat mempengaruhi pelayanan medis dalam memenuhi pelayanan kepada pasien, diperlukan proses yang cepat dalam penyediaan tersebut. Proses tersebut didapat dari hasil pengamatan selama di puskesmas Minggir Sleman dan didukung oleh hasil wawancara yang telah dilakukan peneliti kepada petugas pendaftaran, distribusi dan penyimpanan berkas serta triangulasi dengan kepala Puskesmas di Puskesmas Minggir Sleman.

Hambatan penyediaan berkas rekam medis sampai di poli.

Tabel 6: Hambatan Penyediaan Berkas Rekam Medis

\begin{tabular}{llrrr} 
No & \multicolumn{2}{c}{ Yang Diamati } & Ya & Tidak \\
1. & Ada faktor yang & $\mathrm{V}$ & \\
& menghambat proses & & \\
pendistribusian berkas & & \\
& $\begin{array}{l}\text { rekam medis } \\
\text { poliklinik }\end{array}$ & & \\
\hline
\end{tabular}


Dari hasil wawancara kepada petugas rekam medis, peneliti mendapat hasil bahwa hambatan dari penyediaan berkas itu ada beberapa hal, yaitu belum adanya standar waktu, kesalahan letak dalam rak penyimpanan, berkas masih berada di pelayanan, SDM kurang dan terkadang perawat mengambil sendiri berkas ke pendaftaran.

\section{Sarana}

Sarana yang digunakan dalam penyediaan berkas rekam medis ke poli dari hasil observasi, didapatkan bahwa adanya sarana dalam pendistribusian berkas rekam medis yaitu diantar sendiri oleh petugas.

Tabel 7: Sarana Dalam Penyediaan Berkas Rekam

$$
\text { Medis }
$$

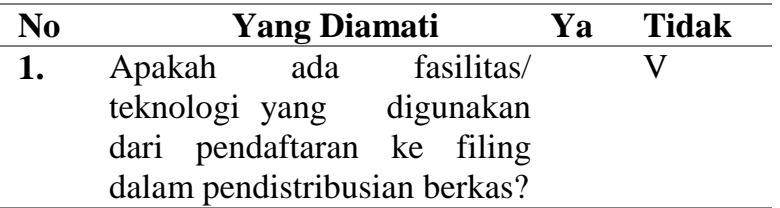

\section{PEMBAHASAN}

Dalam menelusuri faktor yang mempengaruhi keterlambatan penyediaan berkas rekam medis di poli bisa disebabkan karena faktor input meliputi SDM atau petugas rekam medis, sarana dan prasarana, dan manajemen sedangkan proses meliputi kesesuaian SPO dengan pelaksanaan. Berdasarkan Peraturan Menteri Kesehatan RI Nomor 512/Menkes/Per/IV/2007 Tentang Izin Praktik dan Pelaksanaan Praktik Kedokteran BAB 1 pasal 1 ayat 10 Standar Operasional Prosedur adalah suatu perangkat langkah-langkah yang dilakukan untuk menyelesaikan suatu proses kerja rutin tertentu, dimana Standar Operasional Prosedur memberikan langkah yang benar dan terbaik berdasarkan konsensus bersama untuk melaksanakan berbagai kegiatan dan fungsi pelayanan kesehatan berdasarkan standar profesi.

Menurut Priyono 2011 tujuan SOP yaitu: pertama agar petugas menjaga konsistensi dan tingkat kinerja petugas atau tim dalam organisasi atau unit kerja. Yang kedua agar mengetahui dengan jelas peran dan fungsi dari tiap-tiap posisi dalam organisasi. Yang ketiga memperjelas alur tugas, wewenang dan tanggung jawab dari petugas terkait. Yang ke empat melindungi organisasi kerja dan petugas dari malpraktek atau kesalahan administrasi lainnya. Dan yang terakhir untuk menghindari kesalahan, keraguan, duplikasi dan inefisiensi.

Berdasarkan hasil penelitian di Puskesmas Minggir Sleman bahwa SOP merupakan petunjuk dalam melakukan pekerjaan dalam suatu organisasi. SOP distribusi berkas rekam medis di Puskesmas
Minggir Kabupatren Sleman sudah berjalan, namun belum adanya standar (SOP) waktu untuk penyediaan berkas.

\section{Pelaksanaan penyediaan rekam medis di bagian rawat jalan}

Menurut Saputro (2008), pelaksanaan penyediaan berkas rekam medis adalah dalam pendistribusian berkas rekam medis yang cepat dan tepat adalah tujuan utama dalam kegiatan pendistribusian berkas rekam medis yang membawa pengaruh terhadap pemberian pelayanan kesehatan terhadap pasien. Dalam pendistribusian berkas rekam medis diharapkan agar diadakan kegiatan pengecekan kembali antara berkas rekam medis yang disimpan kembali sesuai atau tidak dengan jumlah berkas rekam medis telah di distribusikan sebelumnya dari tindakan pengecekan ini diharapkan. Pendistribusi berkas rekam medis adalah suatu proses penyebaran berkas rekam medis ke tiap-tiap poli yang dituju oleh pasien yang sesuai dengan nomor rekam medis.

Berdasarkan hasil wawancara yang dilakukan dengan responden di Puskesmas Minggir, sudah terdapat SOP distribusi yang mengatur proses distribusi berkas ke poli tujuan pasien. Prosedur tersebut bertujuan sebagai acuan dalam melakukan pekerjaan. Namun demikian dalam proses distribusi tersebut sering dijumpai hambatan-hambatan seperti kesalahan letak di rak penyimpanan. Jika hal ini tidak segera diatasi maka menyebabkan terhambatnya pendistribusian dan pelayanan terhadap pasien.

\section{Hambatan dalam pelaksanaan penyediaan berkas rekam medis}

Menurut (Wijaya 2012), SDM (Sumber Daya Manusia) merupakan sumber daya berupa manusia yang bertanggung jawab terhadap terlaksananya suatu kegiatan. Sumber daya manusia yang mendukung terdistribusinya berkas rekam medis ke poli adalah petugas pendaftaran, penyimpanan dan distribusi.

SDM (Sumber Daya Manusia) sangat penting dalam suatu Puskesmas khususnya bagian rekam medis. Sumber daya manusia yang memenuhi membantu kelancaran pelayanan kesehatan di suatu Puskemas. Berdasarkan hasil wawancara yang dilakukan terhadap petugas rekam medis dan kepala Puskesmas yaitu masih kurangnya sumber daya manusia khususnya yang melakukan distribusi beekas rekam medis, dari petugas pendaftaran yang merangkap ke distribusi dan yang lain. Hal ini menjadi hambatan kelancaran dalam distribusi berkas rekam medis ke poli yang tujuan pasien.

Ketepatan dalam pendistribusian berkas rekam medis sangat penting, jika berkas terlambat sampai poli maka pelayanan kepada pasien terlambat pula. Berdasarkan wawancara kepada Triangulasi, peneliti mendapat hasil bahwa adanya keterlambatan 
distribusi berkas rekam medis sampai poli karena keterbatasan SDM dan menumpuknya pasien baru sehingga petugas harus melengkapi data tersebut. Serta di bagian pendaftaran hanya 3 orang dan mereka bekerja secara merangkap.

\section{SIMPULAN}

1. Standar Operasional Prosedur (SOP) distribusi rekam medis di Puskesmas Minggir sudah berjalan, namun belum adanya standar waktu dalam penyediaan berkas rekam medis.

2. Pelaksanaan penyediaan berkas rekam medis di Puskesmas Minggir belum sesuai dengan SOP distribusi berkas rekam medis.

3. Hambatan pelaksanaan penyediaan berkas rekam medis berdasarkan SOP di Puskesmas Minggir adalah kesalahan letak dalam rak penyimpanan berkas rekam medis, berkas rekam medis masih berada di poli pelayanan dan kurangnya SDM di pendaftaran.

4. Diperlukan adanya perubahan SOP dengan penambahan standar waktu penyediaan berkas rekam medis. Bagi petugas yang berada di poli pelayanan harap segera mengembalikan berkas rekam medis, setelah selesai melakukan pelayanan. Serta petugas filling lebih memaksimalkan penggunaan Tracer.

\section{DAFTAR PUSTAKA}

1. Abdullah, H., 2013. Analisis Kegiatan Pengelolaan Rekam Medis Rawat Inap Pasien Kanker Payudara Program Jamkesmas Untuk Mendukung Pengelolaan Pembiayaan Kesehatan Di Rumah Sakit Islam Sultan Agung Semarang Tahun 2011. Jurnal Kesehatan Masyarakat, 2. Available http://Ejournals1.Undip.Ac.Id/Index.Php/Jkm.

2. Budi, 2011. Manajemen Untuk Kerja Rekam Medis. Yogyakarta: Quantum Sinergis Media

3. Hakam, Fahmi. 2015. Perancangan Sistem Informasi Rekam Medis Di Klinik Griya Medika Menggunakan Metode Prototyping. JURNAL PERMATA INDONESIA

4. Hatta, Gemala R. 2014. Pedoman Manajemen Informasi Kesehatan disarana pelayanan kesehatan. Jakarta: UIP

5. Hozizah, 2014. Kumpulan Peraturan Perundangan Rekam Medis dan Informasi
Kesehatan (Manajemen Informasi Kesehatan). Yogyakarta: Aptirmik Press.

6. Kementrian Kesehatan Republik Indonesia, 2014. Permenkes RI Nomor 75 Tahun 2014, Indonesia.

7. Kementrian Kesehatan RI, 2008. Permenkes No 269 Tahun 2008 Tentang Rekam Medis, Republik Indonesia.

8. Moleong, 2010. Metode Penelitian Kualitatif Edisi Revisi. Bandung: Rosda.

9. Nawawi,H. 2005. Manajemen Sumber Daya Manusia untuk Bisnis Yang Kompetitif. Yogyakarta: MIPAUGM.

10. Peraturan Menteri Kesehatan nomor 55 Tahun 2013. Penyelenggaraan rekam medis. http://ugm.ac.id diakses pada tanggal 18 Februari 2016.

11. Peraturan Menteri Kesehatan RI NO521/Menkes/Per/IV/2007. Izin Praktik dan Pelaksanaan Praktik Kedokterab BAB 1 pasal 1 ayat 10. http://hukumonline.com

12. Rustiyanto, 2011. Manajemen Filing Dokumen Rekam Medis Dan Informasi Kesehatan. Yogyakarta: Politeknik Kesehatan Permata Indonesia.

13. S Utami, AT Susilani, F Hakam. 2016. Hubungan Tingkat Pengetahuan Tentang Rekam Medis Dengan Kelengkapan Pengisian Catatan Keperawatan Pada Instalasi Rawat Inap Di Rumah Sakit At-Turots Al Islamy Sleman. Jurnal Permata Indonesia. Volume, 07, No 01, Mei 2016.

14. Wijaya, I.D., 2012. Analisis dan Perancangan Sistem Informasi Sumber Daya Manusia (SDM) di PT.Inti Karya. Jurnal ELTEK, 10(2), pp.62-76. 